\title{
Correlação fenotípica entre componentes do rendimento de grãos de feijão comum (Phaseolus vulgaris L.)
}

\section{Phenotypic correlation between yield components of common bean (Phaseolus vulgaris L.)}

\author{
Leiri Daiane Barili ${ }^{1 *}$; Naine Martins do Vale ${ }^{1}$; Pedro Patric Pinho Morais ${ }^{1}$; Joana \\ Neres da Cruz Baldissera ${ }^{2}$; Carmelice Boff de Almeida' ${ }^{2}$; Fabiani da Rocha ${ }^{2}$; Giseli \\ Valentini²; Juliano Garcia Bertoldo ${ }^{3}$; Jefferson Luís Meirelles Coimbra ${ }^{4}$; Altamir \\ Frederico Guidolin ${ }^{4}$
}

\begin{abstract}
Resumo
O objetivo deste trabalho foi identificar qual é o componente principal do rendimento de grãos de feijão comum que apresenta menor sensibilidade ao efeito do ambiente, e que propicia maior consistência na expressão dos resultados, quando avaliados em diferentes locais. Os dados experimentais utilizados nas análises são provenientes de Ensaio de Valor cultivo e Uso (VCU) conduzidos nos municípios de Lages e de Chapecó. Os caracteres observados foram estande final de plantas; número de legumes por planta; número de grãos por legume; massa de 1.000 grãos e rendimento total de grãos em $\mathrm{kg} \mathrm{ha}^{-1}$. $\mathrm{O}$ delineamento experimental utilizado foi o de blocos ao acaso, com quatro repetições. As estimativas das correlações fenotípicas foram obtidas pelo método proposto por STEEL e TORRIE e particionadas em efeitos diretos e indiretos mediante a análise de trilha. Correlação inversa foi obtida para os caracteres massa de 1.000 grãos e número de grão por legume, revelando que os mesmos devem ser selecionados conjuntamente para obter ganho no caráter rendimento de grãos. Quando a seleção tem por objetivo aumentar o rendimento de grãos, para as condições ambientais de Chapecó a característica massa de 1.000 grãos pode ser utilizada, enquanto que em Lages o mais apropriado é utilizar o caractere número de legume por planta, pois apresentam consistência e estabilidade no desdobramento dos coeficientes de trilha.
\end{abstract}

Palavras-chave: Phaseolus vulgaris L., potencial produtivo, análise de trilha

\begin{abstract}
This study aimed to identify which is the main component of grain yield of bean that that shows less sensitivity effect of the environment, and provides greater consistency in the expression of
\end{abstract}

\footnotetext{
${ }^{1}$ Alunos de mestrado em Produção Vegetal, Dept ${ }^{\circ}$ de Agronomia, Instituto de Melhoramento e Genética Molecular da UDESC, IMEGEM. Programa de Pós Graduação em Produção Vegetal. Universidade do Estado de Santa Catarina, UDESC/CAV. Av. Luiz de Camões, 2090, Bairro Conta Dinheiro, Caixa Postal 281, CEP 88520-000. Lages, SC. E-mail: leyridaiana@hotmail.com; nainemartinsdovale@hotmail.com; patric_pinho@hotmail.com

2 Mestre em Produção Vegetal, Dept ${ }^{\circ}$ de Agronomia, Instituto de Melhoramento e Genética Molecular da UDESC, IMEGEM. Programa de Pós Graduação em Produção Vegetal. Universidade do Estado de Santa Catarina, UDESC/CAV. Lages, SC. E-mail: carmelice_32@hotmail.com; fabinha_rocha@hotmail.com; valentini_gi@hotmail.com

3 Aluno de doutorado em Recursos Genético Vegetal, Dept ${ }^{\circ}$ de Agronomia, Instituto de Melhoramento e Genética Molecular da UDESC, IMEGEM. Programa de Pós Graduação em Produção Vegetal. Universidade do Estado de Santa Catarina, UDESC/ CAV. Lages, SC. E-mail: jgbertoldo@gmail.com

${ }^{4}$ Profs. Adjunto do CAV/UDESC, Dept ${ }^{\text {}}$ de Agronomia, Instituto de Melhoramento e Genética Molecular da UDESC, IMEGEM. Programa de Pós Graduação em Produção Vegetal. Universidade do Estado de Santa Catarina, UDESC/CAV. Lages, SC. E-mail: coimbrajefferson@cav.udesc.br; altamirguidolin@gmail.com

* Autor para correspondência
}

Recebido para publicação 26/04/2010 Aprovado em 28/06/2011 
results when evaluated in different environments. Experimental data used in the analysis are derived from test of Cultivate and Use Value (VCU) conducted in Lages SC and Chapecó SC, South of Brazil. The characters observed were the final stand of plants, number of pods per plant; number of grains per pod, seed mass (g 1000 seed-1) and grain yield $\left(\mathrm{kg} \mathrm{ha}^{-1}\right)$. The experiment was conducted in a randomized block design, with four replications. Estimates of phenotypic correlations were obtained by the method proposed by STEEL and TORRIE and partitioned into direct and indirect effects through path analysis. The inverse correlation was obtained for the characters of seed mass and grain number per pod, revealing that they should be selected together to obtain gains in the yield character. When the selection is aimed at grain production, for Chapecó-SC the characteristic of seed mass can be used, where as in Lages$\mathrm{SC}$ the character number of grains per pod is more appropriate. Characters seed mass and number of vegetable per pod showed high stability during the unfolding of the path coefficients, showing that they can be used in selecting genotypes with higher grain yield in different environments.

Key words: Phaseolus vulgaris L., grain yield, path analysis

\section{Introdução}

O feijão comum (Phaseolus vulgaris L.) é uma leguminosa que se adapta a diferentes condições edafoclimáticas, onde a temperatura do ar ideal para seu cultivo está na faixa de $21^{\circ} \mathrm{C}$ a $29^{\circ} \mathrm{C}$, (EMBRAPA, 2003) o que permite o seu cultivo em quase todos os estados brasileiros e durante todo o ano, possibilitando uma constante oferta do produto no mercado (BONETT et al., 2006). Apesar de representar um papel fundamental na economia e na dieta da população brasileira, a produtividade de feijão tanto no Brasil quanto em Santa Catarina ainda é baixa, mesmo diante de técnicas de melhoramento empregadas na cultura (BERTOLDO et al., 2009). Um dos principais motivos da baixa produtividade é o fato do mesmo ser produzido em áreas marginais constituídas de solos de baixa fertilidade e por diversas categorias de agricultores, desde a agricultura familiar, com pouco ou sem nenhum uso de tecnologia, até os grandes empresários agrícolas, com utilização das mais modernas tecnologias de produção (MELO et al., 2007). Assim, para viabilizar a cultura do feijão no Estado de Santa Catarina, o desenvolvimento de cultivares melhor adaptadas as condições de ambiente constitui-se em uma prática fundamental para alavancar a produção.

O desenvolvimento de novas cultivares com maior potencial genético para a produtividade é a principal meta dos programas de melhoramento.
Desta forma, o sucesso de tais programas depende da escolha de métodos de melhoramento eficientes que possam atender aos objetivos propostos (CARVALHO et al., 2003). Portanto os programas de melhoramento devem ser cada vez mais eficientes no desenvolvimento de cultivares que tenham boas respostas aos ambientes de cultivo, ou seja, que apresentem elevadas produtividades frente a ambientes desfavoráveis.

Nesse contexto, o melhorista deve lançar mão de técnicas que o auxiliem no momento da seleção para desenvolver cultivares mais produtivas, por meio da correlação entre os caracteres que compõem o rendimento de grãos. Segundo Ribeiro et al. (2010) a seleção indireta nos componentes primários da produção de grãos proporciona a identificação de genótipos superiores. O conhecimento do interrelacionamento entre caracteres é de grande interesse do melhoramento de plantas, e a importância da correlação entre caracteres reside no fato, de se poder avaliar o quanto da alteração de um caráter pode afetar os demais caracteres (SILVA et al., 2009), e assim auxiliar na seleção de genótipos mais produtivos. Neste sentido, identificar os caracteres que evidenciem os maiores efeitos diretos e indiretos sobre o rendimento de grãos é uma das prioridades da pesquisa da cultura do feijão (COIMBRA et al., 1999).

A produtividade de grãos é um caráter complexo, resultante da expressão e da associação 
de diferentes componentes, que são considerados pelo melhorista no processo de seleção de novos genótipos (AMORIM et al., 2008). De acordo com Fehr (1987), o potencial de rendimento de grãos é dependente de processos fisiológicos que podem ter influência direta e/ou indireta sobre este caráter primário e básico. Para que a seleção de genótipos promissores de feijão comum seja eficiente são necessárias informações sobre a natureza e magnitude das variações fenotípicas observadas em uma determinada população. Além disso, deve ser analisado a natureza das correlações de outras características agronômicas com a produtividade, ou entre elas, e sobre a extensão da influência ambiental na expressão das características estudadas (GOMES et al., 2007), uma vez que, a seleção efetuada a campo é aplicada por meio da observação fenotípica das plantas.

Por ser cultivado em quase todo o território nacional e em distintas épocas de semeadura, os genótipos o feijão tem desempenho agronômico diferenciado dependendo das condições ambientais (BURATTO et al., 2007). Tal fato causa influência significativa da interação genótipo $\mathrm{x}$ ambiente no rendimento de grãos (ELIAS et al., 1999), podendo desta forma interferir nas manifestações diretas ou indiretas das características primárias sobre o rendimento de grãos, de acordo com o local e ano de cultivo.

Diversas ferramentas estatísticas tais como a análise de trilha, proposta por Wright (1921), permitem particionar o coeficiente de correlação em efeitos diretos e indiretos (coeficiente de trilha). Assim com a utilização desta técnica, pode-se avaliar se o efeito do ambiente interfere na interrelação dos caracteres. Conforme Cruz e Carneiro (2003) esta análise pode ser definida como um coeficiente de regressão padronizado, sendo uma expansão da análise de regressão múltipla, quando estão envolvidos inter-relacionamentos complexos.

O sucesso da análise de trilha reside basicamente na formulação do relacionamento de causa e efeito entre as variáveis (GONDIM et al., 2008). Além disso, o desdobramento de correlações é dependente do conjunto de caracteres estudados, que normalmente são estabelecidos pelo conhecimento prévio do pesquisador, de sua importância e de possíveis inter-relações expressas em diagramas de trilha (CRUZ; REGAZZI, 1997).

O objetivo deste trabalho foi identificar o componente principal do rendimento de grãos de feijão commenor sensibilidade ao efeito do ambiente, e com maior consistência na expressão dos resultados quando testados em diferentes ambientes, de forma que este possa servir de ferramenta para o melhorista no momento da seleção.

\section{Material e Métodos}

$\mathrm{Na}$ realização deste trabalho foram utilizados dados referentes aos Ensaios de Valor de Cultivo e Uso (VCU), realizados em rede pela EPAGRI Chapecó e pela UDESC Lages. Os experimentos, realizados nos anos agrícolas 2006/07 e 2007/08, foram conduzidos em Lages-SC (latitude de $27^{\circ}$ 49' $\mathrm{S}$ e longitude de $50^{\circ} 20^{\prime} \mathrm{W}$; altitude de 920 $\mathrm{m}$, o clima predominante da região de acordo com köppen é Cfb); e em Chapecó-SC (latitude $27^{\circ} 07^{\prime} \mathrm{S}$ e longitude $52^{\circ} 37^{\prime} \mathrm{W}$ e altitude média de $679 \mathrm{~m}$, o clima predominante da região, pela classificação de Köppen, é do tipo Cfa).

O preparo do solo e as adubações de base e de cobertura foram realizados conforme as necessidades apontadas por meio da análise de solo e as recomendadas para a cultura do feijão de acordo com as recomendações técnicas do Manual de Adubação e de calagem para os estados do RS e SC (2004). O controle de pragas foi efetuado com a aplicação das doses recomendadas de s-metolacloro, e metamidofós (organofosforado), e o controle de plantas invasoras foi realizado com setoxidim (oxima ciclohexanodiona) e manualmente, sempre que necessário, de modo a evitar competição com a cultura. Os ensaios de VCU são conduzidos segundo normas do 
Registro Nacional de Cultivares-RNC/Ministério da Agricultura, Pecuária e Abastecimento- MAPA (MAPA, 2006) onde, uma das avaliações requeridas é a resistência dos genótipos testados a diferentes patógenos, desta forma, não foi efetuado nenhum tratamento fitossanitário.

O delineamento experimental utilizado em todos os ensaios foi de blocos ao acaso, com quatro repetições. Utilizou-se 15 sementes por metro linear, com espaçamento entre linhas de $0,50 \mathrm{~m}$, objetivando população de 250.000 plantas por hectare. A área útil de cada parcela experimental foi constituída das duas fileiras centrais compreendendo 3,6 $\mathrm{m}^{2}$. Após a colheita a umidade dos grãos foi uniformizada para aproximadamente $13 \%$ utilizando estufa de circulação de ar forçada a $460 \mathrm{C}$ por $48 \mathrm{~h}$.

Os caracteres avaliados foram: $i$ ) estande final de plantas (ESTD); ii) número de legumes por planta (NLP); iii) número de grãos por legume (NGL); iv) massa de 1000 grãos em gramas (MMG) e v) rendimento de grãos em $\mathrm{kg} \mathrm{ha}^{-1}$ (REND).

O estande final de plantas foi determinado no momento da colheita e coleta das plantas para avaliação, sendo computado o número de plantas existentes na área útil. O número de legumes por planta foi mensurado por meio da contagem individual dos legumes das plantas avaliadas. Para determinação do número de grãos por legume foi mensurado inicialmente o número total de grãos da planta e então dividido pelo número total de legumes da planta. A massa de mil grãos foi obtida após a secagem dos grãos em estufa de circulação de ar forçada até atingirem a umidade de $13 \%$ onde então foi identificada a massa de 100 grãos e o valor extrapolado para massa de 1000 grãos.

As análises foram realizadas com auxílio dos softwares GENES (CRUZ, 2001) e SAS 9.1 (SAS INSTITUTE, 2008). As estimativas das correlações fenotípicas foram obtidas pelo método proposto por Steel e Torrie (1980) e particionadas em efeitos diretos e indiretos pela análise de trilha Wright (1921).
O grau de multicolinearidade da matriz $\mathrm{X}^{\prime} \mathrm{X}$ foi estabelecido com base no respectivo número de condições (NC), que é a razão entre o maior e o menor autovalor da matriz (MONTGOMERY; PECK, 1981). Nesta análise se $\mathrm{NC}<100$, a multicolinearidade é denominada fraca e não constitui problema para análise; por sua vez, se $100<\mathrm{NC}<1.000$, é considerada de moderada à forte; enquanto que, se $\mathrm{NC}>1.000 \mathrm{o}$ grau de multicolinearidade é determinado como severo. A análise dos autovalores da matriz foi feita para identificar a natureza da dependência linear existente entre os caracteres, detectando aquelas que contribuíram para o aparecimento da multicolinearidade (BELSLEY; KUH; WELSCH, 1980).

\section{Resultados e Discussão}

$\mathrm{Na}$ (Tabela 1) podem ser observados os valores de correlação entre os caracteres primários com o rendimento de grãos, onde se verifica que a massa de mil grãos (MMG) foi o único caráter que apresentou correlação positiva e significativa com o rendimento de grãos (REND) de feijão, no município de Chapecó nos dois anos agrícolas avaliados (0,273 em 2006/07; e 0,269 em 2007/08). Já para o município de Lages o caráter que apresentou correlação positiva e significativa foi o número de legumes por planta NLP $(0,114$ em 2006/07 e 0,115 em 2007/08) demonstrando que esses caracteres influenciaram, de algum modo, a expressão do rendimento total de grãos e não variaram dentro de cada município com a alteração dos anos agrícolas.

A correlação entre caracteres que pode ser diretamente medida é a fenotípica (FALCONER, 1981), sendo que essa correlação possui causas genéticas e ambientais. Entretanto só as causas de origem genéticas envolvem uma associação de natureza herdável, podendo, por conseguinte, ser utilizada na orientação de programas de melhoramento (CRUZ; REGAZZI, 1997). Com base no exposto, pode se verificar que os caracteres 
MMG e NLP para Chapecó e Lages respectivamente, apesar da variação apresentada nos seus valores de um ano de cultivo para o outro, permanecem sendo os mais importantes na composição do rendimento de grãos. Este fato é de suma importância, pois mesmo com o efeito do ambiente sobre o fenótipo, o componente genotípico foi o mais preponderante, desta forma, o ambiente apresentou baixa influência sobre tais caracteres nos anos agrícolas estudados. O efeito da interação genótipo vs ambiente pode levar os diferentes genótipos avaliados a uma ampla diversidade de padrões e resultados (COIMBRA et al., 2009). Esta interação é um fator complicador para a seleção, pois diminui a correlação entre o fenótipo e o genótipo. Desta forma, um caráter que sofre pouca influencia do ambiente, torna-se uma importante ferramenta para auxiliar o melhorista no aprimoramento da característica de interesse, a qual na grande maioria dos programas de melhoramento de feijão é o rendimento de grãos.

Tabela 1. Coeficientes de correlação entre os caracteres massa de 1.000 grãos, número de legumes por planta, número de grãos por legume e estande final de planta com o rendimento de grãos nos municípios de Chapecó e Lages nos anos agrícolas de 2006/07 e 2007/08.

\begin{tabular}{llllll}
\hline Caracteres & Chapecó & Lages & & Chapecó & Lages \\
\cline { 2 - 3 } \cline { 5 - 6 } & & $\mathbf{2 0 0 6 / 0 7}$ & & & $\mathbf{2 0 0 7 / 0 8}$ \\
\hline MMG & $0,273^{*}$ & 0,045 & & $0,269^{*}$ & 0,150 \\
NLP & 0,169 & $0,114^{*}$ & & $-0,359^{*}$ & $0,115^{*}$ \\
NGL & $0,226^{*}$ & $-0,068$ & & $-0,627^{*}$ & $0,206^{*}$ \\
ESTD & $-0,044$ & 0,049 & & $-0,596^{*}$ & $-0,033$ \\
\hline
\end{tabular}

*Significativo a $5 \%$ de probabilidade de erro pelo teste $\mathrm{t}$.

Ainda, na (Tabela 1), pode ser observado que no ambiente de Chapecó no ano de 2006/07 juntamente com MMG, os caracteres que apresentaram correlação positiva com o rendimento de grãos foram, número de legumes por planta $(0,169)$ e número de grãos por legume (0,226). Cabe ressaltar, que no município de Lages no ano de 2006/07 os caracteres massa de mil grãos (MMG) e estande final de plantas (ESTD) apresentaram correlação positiva, porém baixa com o REND, já no ano de 2007/08 os caracteres NGL e MMG apresentaram correlação positiva.

Segundo Montardo et al. (2003) a razão para a baixa correlação entre caracteres é a ocorrência de pouca variabilidade em um dos mesmos, uma vez que esse tipo de análise procura identificar uma eventual associação na variação das características em estudo. Uma das razões que conduziram a restrita variabilidade genética presente em certas culturas, como é o caso do feijão, é a preferência dos produtores e consumidores por determinados ideótipos de planta.

$\mathrm{Na}$ (Tabela 2) estão apresentados os valores do desdobramento da correlação entre as variáveis explicativas e a variável básica, em efeitos diretos e indiretos, obtidos por meio da análise de trilha proposta por Wright (1921). Para fins de melhoramento, é importante identificar dentre as características de alta correlação com a variável básica, aquelas de maior efeito direto em sentido favorável à seleção, de tal forma que a resposta correlacionada por meio da seleção indireta seja eficiente (SEVERINO et al., 2002). 
Tabela 2. Estimativa dos efeitos diretos e indiretos dos componentes da produção sobre a variável principal rendimento de grãos (REND) e variáveis secundárias massa de 1.000 grãos (MMG), número de legumes por planta (NLP), número de grãos por legume (NGL) e estande final de plantas (ESTD) oriundos de ensaio de VCU em Chapecó/SC, nos anos agrícolas de 2006/07 e 2007/08.

Chapecó 2006/07

Chapecó 2007/08

\section{Caracteres}

MMG Efeito direto

Efeito indireto via NLP

Efeito indireto via NGL

Efeito indireto via ESTD

Total

NLP Efeito direto

Efeito indireto via MMG

Efeito indireto via NGL

Efeito indireto via ESTD

Total

NGL Efeito direto

Efeito indireto via MMG

Efeito indireto via NLP

Efeito indireto via ESTD

Total

ESTD Efeito direto

Efeito indireto via MMG

Efeito indireto via NLP

Efeito indireto via NGL

Total

Coeficiente de determinação
Efeito

0,292

0,006

$-0,023$

$-0,002$

0,273

0,109

0,016

0,043

0,001

0,169

0,231

$-0,029$

0,020

0,004

0,226

$-0,016$

0,032

$-0,001$

$-0,059$

$-0,044$

0,604
Caracteres

Efeito

MMG

Efeito direto

0,231

Efeito indireto via NLP $\quad-0,002$

Efeito indireto via NGL $\quad 0,034$

Efeito indireto via ESTD 0,006

Total

0,269

NLP

Efeito direto

0,020

Efeito indireto via MMG -0,024

Efeito indireto via NGL - 0,222

Efeito indireto via ESTD -0,133

Total

$-0,359$

NGL

Efeito direto

$-0,392$

Efeito indireto via MMG -0,023

Efeito indireto via NLP $\quad 0,011$

Efeito indireto via ESTD -0,223

Total

$-0,627$

ESTD

Efeito direto

$-0,247$

Efeito indireto via MMG -0,005

Efeito indireto via NLP $\quad 0,011$

Efeito indireto via NGL $\quad-0,355$

Total

$-0,596$

Coeficiente de determinação
Observa-se na (Tabela 2) que, no ambiente de Chapecó no ano de 2006/07, os caracteres que apresentaram maior efeito direto e positivo com a variável básica REND, foram o MMG (0,292), NGL $(0,231)$ e NLP $(0,109)$, enquanto que no ano de 2007/08 os caracteres que apresentaram o mesmo comportamento foram: MMG $(0,231)$ e NLP $(0,020)$. Autores como, Almeida, Peluzio e Afferri (2010) estudando os efeitos diretos dos componentes primários sobre o rendimento de grãos na cultura da soja, Gondim et al. (2008) e Vieira et al. (2007) em trigo e Coimbra et al. (2004) em canola, também obtiveram valores positivos para estes componentes, evidenciando assim que os efeitos diretos para várias culturas são bons preditores da correlação genética, possibilitando a seleção para rendimento de grãos por meio de seus componentes primários.

O caráter número de legumes por planta é um dos componentes principais da produção na cultura do feijão comum com maior contribuição no rendimento de grãos (KUREK et al., 2001). De 
acordo com Ramalho, Santos e Zimmermann (1993) o número de legumes por planta é o caráter com maior potencial a ser utilizado na seleção, quando o objetivo é incrementar o rendimento de grãos. Desse modo, os caracteres MMG, NLP e NGL podem ser utilizados no melhoramento de feijão quando o objetivo for o aumento do rendimento de grãos. Vale et al. (2009) e Coimbra et al. (1999) encontraram resultados semelhantes de efeito direto e positivo para os caracteres MMG, NLP e NGL em feijão e concluíram que este fato indica que a seleção direta sobre estes caracteres pode ser eficiente para aumentar a produção de grãos por unidade de área.

Ainda na (Tabela 2) é possível verificar que o estande final de plantas (ESTD) tem efeito direto negativo (-0,016 em 2006/07 e -0,247 em 2007/08) com o REND, o que pode estar evidenciando que o aumento na densidade de semeadura acarreta diminuição na produção devido a alta competitividade entre as plantas. Segundo Silva e Carvalho (1977) a competitividade aumenta à medida que ocorre redução do espaçamento entre plantas, devido o aumento da densidade de plantas por $\mathrm{m}^{2}$ (ANDRADE et al., 2001). Por outro lado, analisando conjuntamente os efeitos diretos da MMG e ESTD sobre o REND, pode-se inferir que no município de Chapecó nos dois anos agrícolas estudados, sobre baixa população de indivíduos por $\mathrm{m}^{2}$, as plantas de feijão têm a capacidade de compensação do espaço de forma que a massa de cada grão torna-se maior. Conseqüentemente a MMG contribui para aumento do REND, ratificando que quando se seleciona para maior MMG tem-se maior REND. Segundo Vale et al. (2009) o efeito da competitividade entre as plantas dentro da linha parece ser de extrema importância para incrementar a expressão do efeito genotípico, em detrimento do efeito de ambiente.

$\mathrm{Na}$ (Tabela 3) estão apresentados os valores do desdobramento das correlações fenotípicas para o município de Lages nos anos agrícolas 2006/07 e 2007/08. Observa-se que, houve concordância em ambos os anos de cultivo, para a contribuição dos efeitos diretos dos caracteres MMG, NLPeNGL sobre o rendimento de grãos. Tal fato pode ser comparado com o município de Chapecó, onde, independente do ano agrícola, os genótipos empregados no estudo, comportam-se de forma semelhante, ou seja, o efeito do ambiente não interfere de forma significativa a superar o efeito proporcionado pelo genótipo. Os caracteres supracitados mantiveram-se como os principais componentes do rendimento de grãos nos quatro ambientes estudados. De fato, tais caracteres devem ser observados cuidadosamente pelo melhorista no momento da seleção, quando seu objetivo principal é incrementar o rendimento de grãos, visto que, nos quatro ambientes estudados, estas características correlacionaram-se de forma positiva com o rendimento.

Ainda na (Tabela 3), pode-se observar que o caráter NGL mostrou efeito indireto negativo $(-0,009)$ com o MMG o qual apresentou efeito direto e positivo $(0,036)$ com a variável básica, no ano de 2006/07, o mesmo ocorreu no ano de 2007/08 onde, o efeito direto do caráter MMG foi positivo $(0,155)$ e o efeito indireto via NGL foi negativo $(-0,002)$. Tais resultados podem indicara oposição destas características, ou seja, quando uma planta produz um grande número de grãos por legume, a necessidade de fotoassimilados para o enchimento de todos os grãos, é muitas vezes, maior do que a planta possui, desta forma, ela tende a diminuir a massa dos grãos, o que confere menor massa de mil grãos (MUNDSTOCK; THOMAS, 2005), comprovando a veracidade dos valores supracitados. O inverso também ocorreu, ou seja, quando o NGL apresentou efeito direto e positivo $(0,049)$ com a variável básica, o efeito indireto via MMG foi negativo $(-0,007)$ no ano de 2006/07, bem como no ano de 2007/08 onde o efeito direto do NGL foi positivo $(0,302)$ e o indireto via $\mathrm{MMG}$ foi negativo $(-0,001)$. Esses caracteres merecem destaque no melhoramento, pois quando a seleção for direcionada ao aumento do MMG o efeito indireto do NGL pode afetar negativamente os ganhos com rendimento de grãos. 
Tabela 3. Estimativa dos efeitos diretos e indiretos dos componentes da produção sobre a variável principal rendimento de grãos (REND) e variáveis secundárias massa de 1.000 grãos (MMG), número de legumes por planta (NLP), número de grãos por legume (NGL) e estande final de plantas (ESTD) oriundos de ensaio de VCU em Lages/SC, nos anos agrícolas de 2006/07 e 2007/08.

Lages 2006/07

Lages 2007/08

\begin{tabular}{|c|c|c|c|c|c|}
\hline \multicolumn{2}{|c|}{ Caracteres } & \multirow{2}{*}{$\begin{array}{l}\text { Efeito } \\
0,036\end{array}$} & \multicolumn{2}{|c|}{ Caracteres } & \multirow{2}{*}{$\frac{\text { Efeito }}{0,155}$} \\
\hline $\mathrm{MMG}$ & Efeito direto & & MMG & Efeito direto & \\
\hline & Efeito indireto via NLP & 0,015 & & Efeito indireto via NLP & $-0,002$ \\
\hline & Efeito indireto via NGL & $-0,009$ & & Efeito indireto via NGL & $-0,002$ \\
\hline & Efeito indireto via ESTD & 0,003 & & Efeito indireto via ESTD & $-0,001$ \\
\hline Total & & 0,045 & Total & & 0,150 \\
\hline \multirow[t]{4}{*}{ NLP } & Efeito direto & 0,136 & NLP & Efeito direto & 0,118 \\
\hline & Efeito indireto via MMG & 0,004 & & Efeito indireto via $\mathrm{MMG}$ & $-0,003$ \\
\hline & Efeito indireto via NGL & $-0,034$ & & Efeito indireto via NGL & 0,007 \\
\hline & Efeito indireto via ESTD & 0,009 & & Efeito indireto via ESTD & $-0,007$ \\
\hline Total & & 0,114 & & Total & 0,115 \\
\hline \multirow[t]{4}{*}{ NGL } & Efeito direto & 0,049 & NGL & Efeito direto & 0,302 \\
\hline & Efeito indireto via MMG & $-0,007$ & & Efeito indireto via MMG & $-0,001$ \\
\hline & Efeito indireto via NLP & $-0,095$ & & Efeito indireto via NLP & 0,003 \\
\hline & Efeito indireto via ESTD & $-0,015$ & & Efeito indireto via ESTD & 0,002 \\
\hline Total & & $-0,068$ & Total & & 0,306 \\
\hline \multirow[t]{4}{*}{ ESTD } & Efeito direto & 0,022 & ESTD & Efeito direto & $-0,041$ \\
\hline & Efeito indireto via MMG & 0,005 & & Efeito indireto via $\mathrm{MMG}$ & 0,001 \\
\hline & Efeito indireto via NLP & 0,055 & & Efeito indireto via NLP & 0,021 \\
\hline & Efeito indireto via NGL & $-0,033$ & & Efeito indireto via NGL & $-0,014$ \\
\hline Total & & 0,049 & Total & & $-0,033$ \\
\hline \multicolumn{2}{|c|}{ Coeficiente de determinação } & 0,648 & Coefici & ente de determinação & 0,729 \\
\hline
\end{tabular}

Concordando com as observações dos dois anos de cultivo avaliados no município de Lages, pode-se perceber que os caracteres MMG e NGL comportaram-se da mesma forma em Chapecó, no ano de 2006/07. Devido à homogeneidade dos resultados obtidos para tais características fica evidente a necessidade do estudo destas, devido o fato do MMG ser um dos componentes principais do rendimento de grão. A seleção para o caráter rendimento de grãos pode ser dificultada em programas de melhoramento, devido ao alto valor da contribuição da variância de ambiente, reduzindo a correlação entre o fenótipo e o genótipo (COIMBRA et al., 2009). Porém a partir de um caráter pouco influenciado pelo ambiente, com foi o caso do MMG que apresentou o mesmo padrão de comportamento em três dos quatro ambientes estudados (Tabela 1), a seleção indireta pode ser realizada de forma segura, resultando no incremento no rendimento. 
É importante salientar que os programas de melhoramento são norteados pela demanda dos consumidores e produtores, almejando a melhoria na produção de grãos, nas qualidades nutricionais e outras características de valor comercial (MOOSE; MUMM, 2008), bem como das exigências de alguns nichos de mercado que optam por grãos maiores. Corroborando com Kurek et al. (2001), que afirmam ser a seleção indireta via massa média do grãos a responsável por reduzir consideravelmente o número de grãos por legume, a seleção para aumentar a massa dos grãos de feijão acarreta na diminuição da quantidade legume por planta. $\mathrm{O}$ incremento inversamente proporcional, entre massa dos grãos e número de grãos por legume ocorre, pois, quanto menor o número de legumes por planta, maior é a disponibilidade de fotoassimilados produzidos pela planta para o enchimento dos grãos.

Analisando as (Tabelas 2 e 3) conjuntamente, cabe ressaltar, que os caracteres MMG para Chapecó e Lages em ambos os anos agrícolas e NLP para três dos quatro ambientes estudados, apresentaram valores positivos tanto da correlação com o REND, quanto dos seus efeitos diretos, e ainda que os efeitos indiretos na maioria dos casos mostraram-se positivos e quando negativos de valor insignificante. De acordo com Kurek et al. (2001) e Coimbra et al. (1999) o número de legumes por planta e a massa de 1.000 grãos são os maiores componentes do rendimento de grãos da cultura do feijão e sendo estes caracteres promissores, são de grande contribuição para programas de melhoramento de feijão nos municípios de Chapecó e Lages, pois a seleção direta sobre MMG e NLP pode ser eficiente quando o objetivo é aumentar o rendimento de grãos, pois mesmo com a ação do ambiente, ou seja, da interação genótipo vs ambiente, tais caracteres apresentaram correlação positiva e significativa com o rendimento de grãos (Tabela 1), bem como efeito direto e em sentido favorável a este caráter na maioria dos ambientes estudados (Tabela 2 e 3 ).

A presença da interação entre determinado genótipo a um ambiente, para algumas características, como por exemplo, rendimento de grãos, pode dificultar a recomendação de uma cultivar para grandes áreas geográficas (ARAÚJO et al., 2003). Uma maneira de amenizar a influência da interação genótipo vs ambiente é o desenvolvimento de cultivares específicas para cada região (BACKES et al., 2005). Desta forma, o melhorista podendo lançar mão de um artifício tão importante no momento da seleção, como a análise de trilha para verificar quais as características que apresentam as maiores contribuições para um determinado caráter principal e que se mantém constante com a alteração do ambiente, pode viabilizar a obtenção de novas cultivares de feijão comum com alto potencial produtivo.

\section{Conclusões}

Correlação inversa foi obtida para os caracteres massa de 1.000 grãos e número de grão por legume, indicando que os mesmos devem ser selecionados conjuntamente para obter ganho no caráter principal rendimento de grãos.

Quando a seleção tem por objetivo o aumento no rendimento de grãos, para as condições ambientais de Chapecó a característica massa de 1.000 grãos pode ser utilizada, enquanto que em Lages o mais apropriado é utilizar o caractere número de legume por planta, pois apresentam consistência e estabilidade no desdobramento dos coeficientes de trilha nos diferentes ambientes testados.

\section{Referências}

ALMEIDA, R. D.; PELUZIO, J. M.; AFFERRI, F. S. Correlações fenotípicas, genotípicas e ambientais em soja cultivada sob condições várzea irrigada, sul do Tocantins. Bioscience Journal, Uberlândia, v. 26, n. 1, p. 95-99, 2010.

AMORIM, E. P.; RAMOS, N. P.; UNGARO, M. R. G.; KIIHL, T. A. M. Correlações e análise de trilha em girassol. Bragantia, Campinas, v. 67, n. 2, p. 307-316, 2008.

ANDRADE, M. J. B.; MORAIS, A. R.; TEIXEIRA, I. 
T.; SILVA, M. V. Avaliação de sistemas de consórcio de feijão com Milho-pipoca. Ciência e Agrotecnologia, Lavras, v. 25, n. 2, p. 242-250, 2001.

ARAÚJO, R.; MIGLIORANZA, E.; MONTALVAN, R.; DESTRO, D.; VIDIGAL, M. C. G.; CIRINO, V. M. Genotype $\mathrm{x}$ environment interaction effects on the iron content of common bean grains. Crop Breeding and Applied Biotechnology, Viçosa, v. 3, n. 4, p. 269-274, 2003.

BACKES, R. L.; ELIAS, H. T.; HEMP, S.; NICKNICH, W. Adaptabilidade e estabilidade de genótipos de feijoeiro no estado de Santa Catarina. Acta Scientiarum Agronomy, Maringá, v. 1, n. 2, p. 309-314, 2005.

BELSLEY, D. A.; KUH, E.; WELSCH, R. E. Regression diagnostics: identifying infl uential data and sources of colinearity. New York, USA: J. Wiley, 1980. 292 p.

BERTOLDO, J. G.; COIMBRA, J. L. M.; NODARI, R. O.; GUIDOLIN, A. F.; HEMP, S.; BARILI, L. D.; VALE, N. M.; ROZZETO, D. S. Stratification of the state of Santa Catarina in macro- environments for bean cultivation. Crop Breeding and Applied Biotechnology, Viçosa, v. 9, n. 4, p. 335-343, 2009.

BONETT, L. P.; VIDIGAL, M. C. G.; SCHUELTER, A. R.; FILHO, P. S. V.; GONELA, A.; LACANALLO, G. F. Divergência genética em germoplasma de feijoeiro comum coletado no estado do Paraná, Brasil. Semina: Ciências Agrárias, Londrina, v. 27, n. 4, p. 547-560, 2006.

BURATTO, J. S.; CIRINO, V. M.; JÚNIOR, N. S. F; PRETE, C. E. C.; FARIA, R. T. Adaptabilidade e estabilidade produtiva em genótipos precoces de feijão no estado do Paraná. Semina: Ciências Agrárias, Londrina, v. 28, n. 3, p. 373-380, 2007.

CARVALHO, F. I. F.; LORENCETTI, C.; MARCHIORO, V. S.; SILVA, S. A. Condução de populações no melhoramento genético de plantas. Pelotas: Editora e Gráfica Universitária, UFPel, 2003. 242 p.

COIMBRA, J. L. M.; BERTOLDO, J. B.; ELIAS, H. T.; HEMP, S.; VALE, N. M.; TOALDO, D.; ROCHA F.; BARILI, L. D.; GARCIA, S. H.; GUIDOLIN, A. F.; KOPP, M. M. Mineração da interação genótipo $\mathrm{x}$ ambiente em Phaseolus vulgaris L. para o Estado de Santa Catarina. Ciência Rural, Santa Maria, v. 39, n. 2, p. 355-363, 2009.

COIMBRA, J. L. M.; GUIDOLIN, A, F.; ALMEIDA, M. L.; SANGOI, L.; ENDER, M.; MEROTO, A. J. Análise de trilha dos componentes do rendimento de grãos em genótipos de canola. Ciência Rural, Santa Maria, v. 34, n. 5, p. 1421-1428, 2004.

COIMBRA, J. L. M.; GUIDOLIN, A, F.; CARVALHO,
F. I. F.; COIMBRA, S. M. M.; MARCHIORO, V. S. Análise de trilha I: análise do rendimento de grãos e seus componentes. Ciência Rural, Santa Maria, v. 29, n. 2, p. 213-218, 1999.

CRUZ, C. D. Programa genes: aplicativo computacional em genética e estatística: versão 2001. Viçosa: UFV, 2001. $648 \mathrm{p}$.

CRUZ, C. D.; CARNEIRO, P. C. S. Modelos biométricos aplicados ao melhoramento genético. Viçosa: UFV, 2003. $585 \mathrm{p}$.

CRUZ, C. D., REGAZZI, A. J. Modelos biométricos aplicados ao melhoramento genético. Viçosa: UFV, 1997. $390 \mathrm{p}$.

ELIAS, F.; CLARKE, S. M.; PECK, R.; TERENTJEV, E. M. Equilibrium textures in main-chain liquid crystalline polymers. Europhysics Letters, Les Ulis, v. 47, n. 4, p. 442-448, 1999.

EMPRESA BRASILEIRA DE PESQUISA AGROPECUÁRIA - EMBRAPA. Feijão: o produtor pergunta, a Embrapa responde. Brasília: Embrapa Informação Tecnológica, 2003. 203 p.

FALCONER, D. S. Introdução à genética quantitativa. Viçosa: UFV, 1981. 279 p.

FEHR, W. R. Principles of cultivars development. New York: Macmillan Publishing Company, 1987. v. 1, 536 p.

GOMES, C. N.; CARVALHO, S. P.; JESUS, A. M. S.; CUSTÓDIO, T. N. Caracterização morfoagronômica e coeficientes de trilha de caracteres componentes da produção em mandioca. Pesquisa Agropecuária Brasileira, Brasília, v. 42, n. 8, p. 1121-1130, 2007.

GONDIM, T. C. O.; ROCHA, V. S.; SEDIYAMA, C. S.; MIRANDA, G. V. Análise de trilha para componentes do rendimento e caracteres agronômicos de trigo sob desfolha. Pesquisa Agropecuária Brasileira, Brasília, v. 43, n. 4, p. 487-493, 2008.

KUREK, A. J.; CARVALHO, F. I. F.; ASSMANN, I. C.; MARCHIORO, V. S.; CRUZ, P. J. Análise de trilha como critério de seleção indireta para rendimento de grãos em feijão. Revista Brasileira de Agrociência, Pelotas, v. 7, n. 1, p. 29-32, 2001.

MINISTÉRIO DA AGRICULTURA, PECUÁRIA E ABASTECIMENTO - MAPA. Formulário para registro de cultivares e requisitos para VCU. 2006. Disponível em: <http://www.agricultura.gov.br>. Acesso em: 02 ago. 2009.

MELO, J. O.; ENDO, T. H.; BERSANI-AMADO, L. E.; SVIDZINSKI, A. E.; BARONI, S.; MELLO, J. C. P.; BERSANI-AMADO, C. A. Effect of Stryphnodendron adstringens (barbatimão) bark on animal models 
of nociception. Revista Brasileira de Ciências Farmacêuticas, São Paulo, v. 43, n. 3, p. 465-469, 2007.

MONTARDO, D. P.; AGNOL, M. D.; CRUSIUS, A. F.; PAIM, E. N. R. Análise de trilha para rendimento de sementes de trevo vermelho (Trifolium pratense L.). Revista Brasileira de Zootecnia, Viçosa, v. 32, n. 5, p. 1076-1082, 2003.

MONTGOMERY, D. C.; PECK, E. A. Introduction to linear regression analysis. New York: J. Wiley, 1981. $504 \mathrm{p}$.

MOOSE, S. P.; MUMM, R. H. Molecular plant breeding as the foundation for $21^{\text {st }}$ century crop improvement. Plant Physiology, Palo Alto, v. 147, n. 1, p. 969-977, 2008.

MUNDSTOCK, C. M.; THOMAS, A. L. Soja: fatores que afetam o crescimento e o rendimento de grãos. Porto Alegre: Departamento de Plantas de Lavoura da Universidade Federal do Rio Grande do Sul: EVANGRAF, 2005. $30 \mathrm{p}$.

RAMALHO, M. A. P.; SANTOS, J. P.; ZIMMERMANN, M. J. O. Genética quantitativa em plantas autógamas: aplicações ao melhoramento do feijoeiro. Goiânia: UFG, 1993. $271 \mathrm{p}$.

RECOMENDAÇÕES TÉCNICAS DA COMISSÃO DE QUÍMICA E FERTILIDADE DO SOLO. Manual de adubação e de calagem para os Estados do RS e SC. 10. ed. Porto Alegre: Sociedade Brasileira de Ciência do Solo-Núcleo Regional Sul, 2004. 394 p.

RIBEIRO, N. D.; CARGNELUTTI FILHO, A.; POERSCH, N. L.; ROSA, D. P. Critério de seleção indireta para a produtividade de grãos em feijão. Ciência Rural, Santa Maria, v. 40, n. 4, p. 986-989, 2010.

SAS Institute Inc. SAS® 9.1.3 (TS1M3) for Windows Microsoft. Cary: SAS Institute Inc, 2007. 212 p.

SEVERINO, L. S.; SAKIYAMA, N. S.; PEREIRA, A. A.; MIRANDA, G. V.; ZAMBOLIM, L.; BARROS, U. V. Associações da produtividade com outras características agronômicas de café (Coffea arabica L. "Catimor"). Acta Scientiarum Agronomy, Maringá, v. 24, n. 5, p. $1467-$ 1471, 2002.

SILVA, A. C. F.; CARVALHO, F. I. F. Estimativa dos efeitos da competição intergenotípica através do uso de genes marcados em trigo (Triticum aestivum L.): Mistura mecânica de cultivares. Ciência e Cultura, São Paulo, v. 30, n. 10, p. 533-541, 1977.

SILVA, M. A.; SILVA, D. S.; ANDRADE, L. A.; LOPES, W. B.; SANTOS, G. R. A. Análise de trilha para caracteres morfológicos do feijão-bravo (capparis flexuosa) no cariri paraibano. Archivos de Zootecnia, Cordoba, v. 58, n. 221, p. 121-124, 2009.

VALE, N. M.; BARILI, L. D.; ROCHA, F.; ROZZETTO, D. S.; PEREIRA, T. P.; COIMBRA, J. L. M.; GUIDOLIN, A. F.; BERTOLDO, J. G. Métodos de semeadura empregados como critério de avaliação fenotípica em melhoramento de feijão. Biotemas, Florianópolis, v. 22, n. 4, p. 73-81, 2009.

VIEIRA, E. A.; CARVALHO, F. I. F.; OLIVEIRA, A. C.; MARTINS, L. F.; BENIN, J.; SILVA, J. A. G.; COIMBRA, J. L. M.; MARTINS, A. F.; CARVALHO, M. F.; RIBEIRO, G. Análise de trilha entre os componentes primários e secundários do rendimento de grãos em trigo. Revista Brasileira de Agrociência, Pelotas, v. 13, n. 2, p. 169-174, 2007.

WRIGHT, S. Correlation and causation. Journal of Agricultural Research, Lahore, v. 20, n. 7, p. 557-585, 1921. 
Barili, L. D. et. al. 